\title{
Studies on Strength and Related Properties of Concrete Incorporating Aggregates from Demolished Wastes: Part 1-A Global Perspective
}

\author{
Shodolapo Oluyemi Franklin1, Mmasetlhomo Tommy Gumede ${ }^{2}$ \\ ${ }^{1}$ Department of Civil Engineering, Faculty of Engineering and Technology, University of Botswana, Gaborone, \\ Botswana \\ ${ }^{2}$ Norvels (Pty) Ltd T/A Engineers International, G. West Industrial, Gaborone, Botswana \\ Email: franklinso@mopipi.ub.bw, tgooms05@yahoo.com
}

Received 30 September 2014; revised 20 October 2014; accepted 4 November 2014

Copyright $@ 2014$ by authors and Scientific Research Publishing Inc.

This work is licensed under the Creative Commons Attribution International License (CC BY).

http://creativecommons.org/licenses/by/4.0/

(c) (i) Open Access

\begin{abstract}
The present study addresses the global concern of sustainability in building and construction engineering and how to an extent the use of demolished aggregate wastes in concrete production contributes towards ameliorating or minimizing the problem. The influence of demolished aggregate waste on the mechanical strength and stiffness of concrete are examined from the standpoint of the compressive, split tensile and flexural strengths as well as the modulus of elasticity of the concrete. In this respect the research carried out by previous investigators are noted. It is observed that in the Southern African region in general and Botswana in particular there is a paucity of studies on the subject, and consequently, it is concluded that further investigations need to be conducted utilizing aggregates derived from local wastes or sources.
\end{abstract}

Keywords

Sustainability, Demolished Aggregates, Wastes, Concrete, Strength

\section{Introduction}

Sustainability has been defined as the improvement in the quality of human life while living within the carrying capacity of supporting eco-systems. However, apart from its reference to human well-being, it has also been defined in terms of the global balance of production and consumption. It infers responsible and pro-active decision 
making and innovation that significantly reduces any negative impact and maintains the balance between social, environmental and economic growth to ensure a desirable planet earth for all forms of life presently and well into the future (Milne et al. [1]). Another closely allied concept and equally fashionable is the term "sustainable development”, defined by the Brundtland Commission of the United Nations [2] as the development that fulfills present needs without compromising the ability of future generations to satisfy their own requirements.

Of relevance to the issue of sustainability is the idea of environmental management which attempts to reduce negative human impact and enhance ecosystem delivery. In respect of the earth's raw materials, it is projected that by the year 2050, 140 billion tons of minerals, ores, fossil fuels and biomass per year (three times the present amount) could be consumed unless the economic growth rate is detached or de-coupled from the rate of natural resource consumption (UNEP [3]). As a consequence, dematerialization, or the switch from the linear path of materials (or from extraction to use to ultimate disposal in landfill) to a circular material flow that reuses materials as much as practicable, has been embraced. From a life cycle perspective, it is obvious that the use of sustainable biomaterials obtained through renewable means or recycling offers significant advantages compared to the utilization of non-renewable resources.

The above considerations are of crucial importance in building and civil engineering. In support of this assertion the American Society of Civil Engineers [4] in its Policy Statement 418 entitled "The Role of the Civil Engineer in Sustainable Development” has stressed the leadership role of engineers in sustainable development and the necessity to provide effective and innovative solutions in addressing the problems or challenges of sustainability. The reality of limited natural resources should be recognized and hence the need for sustainable practices involving life cycle analysis and sustainable design approaches cannot be over-estimated. In a similar vein the Royal Academy of Engineering UK [5] in its report "Engineering for Sustainable Development: Guiding Principles" has described sustainable development as the process of development or evolution where the socio-economic and techno-centric concerns are kept within the eco-centric concerns, or the human expectations and aspirations are satisfied by developing skills of engineers and an economic system in a manner that the eco-centric concerns are fulfilled, in other words, in a way that the earth can sustain humanity. It is argued that since it is civil engineers who lead the decision making process about materials usage, energy resources, infrastructure development etc., they must feature prominently and take the lead in sustainable development, constantly proposing available alternatives that satisfy the needs of clients in a sustainable manner.

Building and civil engineering activities such as clearing of land, excavation, construction, remodeling, repair and demolition of such infrastructures like buildings, bridges, roads and other utilities result in solid wastes of which a significant proportion is Construction and Demolition (CD) waste. Most of the latter is used in landfills and include bricks, concrete and other masonry materials, soil mixed with other CD debris, rock, wood, wall covering, plaster, drywall reclaimed asphalt pavement, glass, etc. However continuous industrial development coupled with the ever increasing world population and the consequent reduction in availability of landfill space poses serious problems, not only in respect of availability of natural aggregate for the production of new concrete, but also with reference to CD waste disposal (Chandra [6] [7]). It is obvious that in the conservation of natural resources with respect to the construction sector, the recycling and reuse of CD wastes represent a logical way of solving the afore-mentioned problem (Khalaf and de Venny [8]). With proper planning the amount of waste earmarked or destined for landfills from the construction industry could be minimized, thus helping to conserve scarce natural resources, lowering waste disposal costs and ultimately protecting the environment.

\section{Use of Demolished Aggregates}

Since they constitute a major portion of total solid waste production in the world, CD waste could be recycled and the resulting aggregates used in everyday concrete production. CD waste is produced when roads, buildings, bridges and other engineering works are demolished or maintained. Recycling is the act of processing the previously used material for use in creating new products, and involves breaking, removing and crushing existing concrete into a material with a specified size and quality. Hence recycled aggregate (RA) is derived from demolition of buildings, bridges, roads, and other civil engineering infrastructures. The concrete manufactured using such aggregates is termed as recycled aggregate concrete (RAC). Ismam and Ismail [9] in reviewing the approach adopted in strategic management for waste management in China and Hong Kong amongst others have noted that recycled aggregate is accepted as a sustainable construction material.

Generally speaking, unprocessed recycled aggregates are used for bulk fill, bank protection, for drainage 
structures as base or fill, construction of roads, noise barriers and embankments. The majority of the unprocessed crushed concrete aggregate is sold as $37.5 \mathrm{~mm}$ or $50 \mathrm{~mm}$ fraction for pavement sub-bases. After contaminants are removed by selective demolition, screening, air separation and size reduction in a crusher to aggregate sizes, the crushed concrete aggregates can be used in new concrete. This RAC is commonly utilized in pavements, curbs and gutters, bridge foundations, structural grade concrete and bituminous concrete, amongst others (Portland Cement Association [10]).

Several investigators have carried out studies on the use of demolished aggregates in concrete. Notable amongst previous researches are the studies of Rao et al. [11], Rakshvir and Barai [12], Wagih et al. [13], etc. A very comprehensive summary of the various investigations to date on the subject is presented by de Brito and Saikia [14]. However, in the current paper the emphasis is not on usage of RAC, but rather, on the assessment of the influence of demolished aggregates on the mechanical strength and stiffness of concrete, or more particularly, the compressive and flexural strengths as well as the modulus of elasticity of the concrete. The exercise has been executed primarily through a succinct review of the work carried out by past investigators to date on the subject. Some attention has been paid to investigations or findings in the South African sub-continent where there has been less awareness of the need for sustainability management or sustainable development, compared to other technologically more advanced societies.

\section{Compressive Strength of Recycled Aggregate Concrete}

In their studies in Kharagpur, India on RAC, Rakshvir and Barai [12] found that the properties of the original concrete influenced the mechanical properties of RAC. They noted that the compressive strength of RAC is generally lower than that of conventional concrete made from similar mix proportions. The amount of reduction in strength depended on parameters such as grade of demolished concrete, replacement ratio, water-cement ratio, processing of recycled aggregate, etc. The compressive strength decreased with increasing amounts of recycled aggregates, the variation being in the range 5\% - 15\%, with the upper limit representing a replacement of natural aggregates by recycled aggregates in the proportion $75 \%$ by weight.

Richardson et al. [15] reported that ungraded recycled demolition waste resulted in a 54\% strength reduction when compared to the control sample. However grading the recycled aggregate and washing out the fine material reduced the strength loss of the recycled demolition waste aggregate concrete to $28 \%$ in comparison with the plain control specimen manufactured from virgin aggregates. It was suggested that although this strength reduction was quite significant, it was influenced by the type of recycled aggregate as well as the aggregate condition in terms of shape, porosity and fine material present.

Guan [16] conducted compressive strength tests in Singapore on concrete of three different water-cement ratios $0.57,0.50$ and 0.43 . He replaced natural aggregates with Grade 20 recycled concrete aggregate (RCA) in the proportions $25 \%, 50 \%, 75 \%$ and $100 \%$. He found that all three mixes were able to achieve approximately a minimum of $98 \%$ of the natural aggregate concrete strength when replacement percentages were kept below 25\%. The cube strength reduced with an increasing RCA content.

Ahmad et al. [17] investigated the properties of concrete made with North Carolina recycled coarse and fine aggregates. The results showed that concrete strength decreases approximately linearly with increasing percentage of recycled fine aggregate in lieu of natural fine aggregate. The overall strength reduction was relatively insensitive to the age of the concrete as well as the amount of recycled fine aggregate used in the mixture. For concretes with $60 \%$ recycled concrete aggregate and older than 14 days, the decrease in compressive strength for the mixtures with $100 \%$ recycled fines was approximately $25 \%$ to $30 \%$ of the mixtures with all natural fine aggregates.

The results of a study conducted on behalf of RILEM by Hansen [18] revealed that the compressive strength of RAC was between $14 \%$ and $32 \%$ lower than that of conventional concrete. Furthermore RAC consisting of coarse recycled aggregate and natural sand but possessing the same compressive strength as comparable conventional concrete made with natural aggregate for similar water-cement ratios could be produced. It was argued that the compressive strength of recycled aggregates is governed by the strength of the original concrete and is largely dependent on the combination of the water-cement ratios of the original and the recycled concrete where all other factors are basically identical. For situations where the water-cement ratio of the original concrete is the same or lower than that of the recycled concrete, then the strength of the latter can be equivalent or exceed that of the original concrete. 


\section{Splitting Tensile and Flexural Strengths}

The average splitting tensile and flexural strengths of RAC are lower than that for natural aggregate concrete. Their reduction ranges from $5 \%$ to $12 \%$ for splitting tensile strengths, and $4 \%$ to $15 \%$ for flexural strengths, according to Singh and Sharma [19]. A study by Kumutha and Javai [20] indicated that for recycled aggregates obtained from crushed concrete, as the percentage of recycled aggregates increased from $20 \%$ to $80 \%$, the reduction in splitting tensile strength was in the range 5\% - 31\%. The corresponding reduction for flexural strength was $20 \%-47 \%$.

Ahmad et al. [17] observed a linear decrease in splitting tensile strengths with increasing percentages of recycled fine aggregates. At 28 days for concrete with 100\% recycled fine aggregate, the overall decrease in splitting tensile strength was $18 \%$ - $27 \%$ in comparison with concrete made $100 \%$ natural fine aggregate. The corresponding value in respect of flexural strength was $15 \%-20 \%$.

Hansen [18] indicated that the flexural strength of recycled concrete is approximately $12.5 \%-20 \%$ of the compressive strength. These values are comparable to that for conventional concrete. Notwithstanding, Rakshvir and Barai [12] found that both the splitting tensile and flexural strengths of recycled gravel aggregate concrete were up to $10 \%$ lower than the natural aggregate concrete for the range $0 \%-50 \%$ replacement.

Katz [21] has noted that the ratios of flexural and splitting tensile strengths to the compressive strength were in the ranges of $16 \%-23 \%$ and $9 \%$ - 13\%, respectively for recycled ordinary Portland cement and white Portland cement concretes taken together. He opined that these values are relatively high in comparison with the recommendations of ACI 363R for the recycled ordinary Portland cement concrete in particular.

A study by Rao [22] suggests a reduction in strength of $15 \%-20 \%$ in relation to natural concrete for $100 \%$ replacement. In another investigation where high strength and high performance concretes were of primary interest, it was noted that the tensile strengths of recycled aggregate and natural aggregate concretes differed by less than 10\% (Ajdukiewicz and Kliszczewicz [23]).

Guan [16] reported that there is about 25\% - 30\% decrease in tensile strength for concrete made with recycled aggregate produced from $30 \mathrm{MPa}$ concrete or recycled coarse aggregate obtained by crushing concrete from unknown sources such as a dump site.

\section{Modulus of Elasticity}

Singh and Sharma [19] found that the static modulus of elasticity for the recycled aggregate concrete is lower than that of natural aggregate by a maximum margin of 15\%. They suggest that this was on account of the higher proportion of hardened cement paste in the RAC. Ahmad et al. [17] reported that all the concrete made with 60\% RCA showed an overall decrease in modulus of elasticity as the percentage of recycled fine aggregate was increased. However, similar to the case of compressive strength, such reductions were sensitive to the age of the concrete. It was concluded that for concrete with 60\% RCA the decrease in elastic modulus for mixtures with $100 \%$ recycled fines was approximately $28 \%$ - $40 \%$ of that for mixtures with $100 \%$ natural fine aggregates. According to Hansen [18] due to the large amount of old mortar with a relatively low modulus of elasticity which adheres to original aggregate particles in recycled aggregates, the modulus of elasticity of RAC should be expected to be lower than that of the reference concrete made with natural aggregates.

Rao et al. [11] have pointed out that the modulus of elasticity for RAC has been found by several investigators to be in the range $50 \%-70 \%$ of conventional concrete. However the value is dependent on the water-cement ratio and the replacement proportion of recycled aggregate. Guan [16] has noted that the modulus of elasticity of both parent and recycled aggregate concretes is related to the compressive strength; for a given strength of concrete, the modulus of elasticity of RAC is lower than that for the parent concrete.

\section{General Discussion}

Although researchers have reported a reduction in strength of recycled aggregate when compared to conventional concrete, it appears that the extent of the reduction is dependent on factors such as the type of concrete used for obtaining the recycled aggregate whether high, medium or low strength, the replacement ratio, water-cement ratio and the moisture condition of the recycled aggregate (Rao et al. [11]). It is also noted that the strength of RAC and reference concrete may be comparable even at $100 \%$ replacement, provided that the water-cement ratio is not higher than 0.55 . However, as the water-cement ratio is reduced to 0.40 , the strength of RAC may generally be no more than $75 \%$ of the reference mix. Kumutha and Vijai [20] have noted that concrete specimens 
with greater replacement proportion of recycled aggregate have lower compressive strength when compared to concrete samples with less recycled aggregates. This was the case whether crushed concrete or crushed brick was used to produce the recycled coarse aggregate. Tempest et al. [24] have concluded that structural compressive strength can be developed in concretes incorporating up to $100 \%$ recycled aggregate using standard mixing procedures and economical mix designs.

In a similar manner to compressive strength, the splitting tensile and flexural strengths of RAC have been found to be generally lower than that for reference concrete. At 28 days, as the percentage of recycled aggregate fell in the range $80 \%-100 \%$, the reduction in splitting tensile or flexural strengths appeared to be in excess of $20 \%$ in most cases. On average it is noted that the ratio of flexural strength to compressive strength for RAC was $15 \%-22 \%$ while the corresponding value for splitting tensile strength was about $9 \%-13 \%$. The flexural strength ratios are comparable to that of conventional concrete according to Hansen [18]. However, when viewed in relation to the ACI 363R recommendations for recycled ordinary Portland cement concrete, these values are relatively high.

In respect of modulus of elasticity, all investigations indicate that concretes with natural coarse aggregates have the highest values while concretes with $100 \%$ recycled aggregates have the lowest modulus of elasticity. Reductions of the order of $40 \%$ have been noted in several instances. This reduction is attributed to the large proportion of old mortar with a comparatively low modulus of elasticity adhering to the original aggregate particles in recycled concrete (Hansen [18]).

It has not been possible to find investigations in the literature of a similar manner reported herein with reference to the Southern African region. Most of the investigations appear to be in respect of waste management practices. For instance Macozoma [25] reported that in South Africa there are over 1 million tonnes of building rubble reaching landfill sites every year throughout the country with the construction industry generating about 5 to 8 million tonnes of waste yearly. However, the recycling of rubble is limited to single operations in Western Cape, Kwa-Zulu Natal and Gauteng. In addition he noted that there is much CD material waste reuse for aspects such as landfills and informal housing. Nevertheless a lot of these applications are for low-level usage. In respect of Botswana, Kgosiesele and Zhaohui [26] report that there is no national database on quality of waste generated. Furthermore they assert that there is insufficient waste management; the wastes from construction and demolition are not recycled, but rather a high proportion is illegally dumped in the outskirts of cities and towns. Bolaane [27] has observed that although the benefits of recycling are known in Botswana, the attitude of local government personnel is not to embrace waste management developments like recycling. Rather, conventional waste collection and disposal is favoured while recycling is left to private sector initiatives. Hence it can be safely concluded that apart from CD waste management procedures and practices, little or no investigation on strength or related properties of concrete incorporating aggregates from demolished wastes has been carried out in the Southern African sub-continent.

\section{Conclusion}

The present work, albeit a comprehensive review, represents a preliminary portion of an on-going investigation by the authors on the assessment of the strength of concrete incorporating aggregates from demolished wastes. The investigation is expected to include experimental studies involving demolished concrete wastes collected from some major dump sites in Gaborone the capital city of Botswana. From the study carried out herein, a number of conclusions may be drawn. It is obvious that structural compressive strengths may be developed in concretes incorporating up to $100 \%$ recycled aggregates based on standard mix design procedures. We note also that the compressive, split tensile and flexural strengths, as well as the modulus of elasticity of recycled aggregate concretes, are generally lower than that of conventional concretes made entirely from natural aggregates. The reduction in strength is dependent on several factors such as the type of concrete used in obtaining the recycled aggregates, the replacement ratio, the water-cement ratio and the moisture condition of the recycled aggregates. Additionally we observe that in the Southern African sub-continent including Botswana, apart from investigations on construction waste management practices, there has been practically no study to the best of the authors' knowledge on the relative strength of concrete incorporating aggregates from demolished wastes.

\section{References}

[1] Milne, M.J., Kearins, K. and Walton, S. (2006) Creating Adventures in Wonderland: The Journey Metaphor and Envi- 
ronmental Sustainability. Organization, 13, 801-839. http://dx.doi.org/10.1177/1350508406068506

[2] United Nations General Assembly (1987) Report of the Working Commission on Environment and Development: Our Common Future. Transmitted to the General Assembly as an Annex to Document A/42/427-Development and International Co-Operation: Environment, Our Common Future, Chapter 2. http://en.wikipedia.org/wiki/Sustainability

[3] UNEP (2011) De-Coupling Natural Resource Use and Environmental Impacts from Economic Growth. Report of the Working Group on De-Coupling to the International Resource Panel, United Nations Environment Programme, Nairobi.

[4] American Society of Civil Engineers (2013) Policy Statement 418-The Role of the Civil Engineer in Sustainable Development. Adopted by the Board of Direction on October 8, 2013. http://www.asce.org/Public-Policies-and-Priorities/Public-Policy-Statements/Policy-Statement-418---The-Role-of-theCivil-Engineer-in-Sustainable-Development/

[5] The Royal Academy of Engineering (2005) Engineering for Sustainable Development: Guiding Principles. The Royal Academy of Engineering, London.

[6] Chandra, S. (2004) Implications of Using Recycled Construction and Demolition Waste as Aggregate in Concrete. Session Lead Paper. Proceedings of the International Conference on Sustainable Waste Management and Recycling, Kingston University, London, 14-15 September 2004. In: Limbachiya, M.C. and Roberts, J.J., Eds., Sustainable Waste Management and Recycling: Challenges and Opportunities. Volume 2-Construction Demolition Waste, Thomas Telford Publishing, London, 105-114.

[7] Chandra, S. (2005) Conference Report. Cement and Concrete Composites, 27, 738-741. http://dx.doi.org/10.1016/j.cemconcomp.2005.01.001

[8] Khalaf, F.M. and DeVenny, A.S. (2004) Recycling of Demolished Masonry Rubble as Coarse Aggregate in Concrete: Review. ASCE Journal of Materials in Civil Engineering, 16, 331-340. http://dx.doi.org/10.1061/(ASCE)0899-1561(2004)16:4(331)

[9] Ismam, J.N. and Ismail, Z. (2014) Sustainable Construction Waste Management Strategic Implementation Model. WSEAS Transactions on Environment and Development, 10, 48-59.

[10] Portland Cement Association (2011) Recycled Aggregates. Materials Concrete Technology. http://cement.org/tech/index.asp

[11] Rao, A., Jha, K.N. and Misra, S. (2007) Use of Aggregates from Recycled Construction and Demolition Waste Concrete. Resources, Conservation and Recycling, 50, 71-81. http://dx.doi.org/10.1016/j.resconrec.2006.05.010

[12] Rakshvir, M. and Barai, S.V. (2006) Studies on Recycled Aggregate-Based Concrete. Waste Management \& Research, 24, 225-233. http://dx.doi.org/10.1177/0734242X06064820

[13] Wagih, A.M., El-Karmoty, H.Z., Ebid, M. and Okba, S.H. (2012) Recycled Construction and Demolition Waste as Aggregate for Structural Concrete. HBRC Journal, 9, 193-200. http://dx.doi.org/10.1016/j.hbrcj.2013.08.007

[14] De Brito, J. and Saikia, N. (2013) Recycled Aggregate in Concrete: Use of Industrial, Construction and Demolition Waste. Green Energy and Technology, Springer-Verlag, London. http://dx.doi.org/10.1007/978-1-4471-4540-0

[15] Richardson, A., Allain, P. and Veuille, M. (2010) Concrete with Crushed, Graded and Washed Recycled Construction Demolition Waste as a Coarse Aggregate Replacement. Structural Survey, 28, 142-148. http://dx.doi.org/10.1108/02630801011044244

[16] Guan, J.L.L. (2011) Effects of Recycled Aggregates on Concrete Properties. Master of Engineering Thesis, National University of Singapore, Singapore.

[17] Ahmad, S.H., Fisher, D.G. and Sackett, K.W. (1996) Properties of Concrete Made with North Carolina Recycled Coarse and Fine Aggregates. Centre for Transportation Engineering Studies, North Carolina State University, Raleigh.

[18] Hansen, T.C. (1992) Recycling of Demolished Concrete and Masonry. Report of Technical Committee 37-DRC Demolition and Reuse of Concrete, RILEM, E \& FN Spon, London.

[19] Singh, S.K. and Sharma, P.C. (2007) Use of Recycled Aggregates in Concrete-A Paradigm Shift. Journal of New Building Materials and Construction World, 13, 173-183. http://www.nbmcw.com/articles/concrete/576-

[20] Kumutha, R. and Vijai, K. (2010) Strength of Concrete Incorporating Aggregates Recycled from Demolition Waste. ARPN Journal of Engineering and Applied Sciences, 5, 64-71.

[21] Katz, A. (2003) Properties of Concrete Made with Recycled Aggregate from Partially Hydrated Old Concrete. Cement and Concrete Research, 33, 703-711. http://dx.doi.org/10.1016/S0008-8846(02)01033-5

[22] Rao, A. (2005) Experimental Investigation on Use of Recycled Aggregates in Mortar and Concrete. Thesis Submitted to the Department of Civil Engineering, Indian Institute of Technology Kanpur, Kanpur.

[23] Ajdukiewicz, A. and Kliszczewicz, A. (2002) Influence of Recycled Aggregates on Mechanical Properties of HS/HPC. Cement and Concrete Composites, 24, 269-279. http://dx.doi.org/10.1016/S0958-9465(01)00012-9

[24] Tempest, B., Cavalline, T., Gergely, J. and Weggel, D. (2010) Construction and Demolition Waste Used as Recycled 
Aggregates in Concrete: Solutions for Increasing the Marketability of Recycled Aggregate Concrete. Concrete Suitability Conference, University of North Carolina, Charlotte, Tempe, 13-15 April 2010, 1-15.

[25] Macozoma, D.S. (2006) Developing a Self-Sustaining Secondary Construction Materials Market in South Africa. Master of Science Dissertation, University of the Witwatersrand, Johannesburg.

[26] Kgosiesele, E. and Zhaohui, L. (2010) An Evaluation of Waste Management in Botswana: Achievements and Challenges. Journal of American Sciences, 6, 144-150.

[27] Bolaane, B. (2006) Constraints to Promoting People Centred Approaches in Recycling. Habitat International, 30, 731740. http://dx.doi.org/10.1016/j.habitatint.2005.10.002 
Scientific Research Publishing (SCIRP) is one of the largest Open Access journal publishers. It is currently publishing more than 200 open access, online, peer-reviewed journals covering a wide range of academic disciplines. SCIRP serves the worldwide academic communities and contributes to the progress and application of science with its publication.

Other selected journals from SCIRP are listed as below. Submit your manuscript to us via either submit@scirp.org or Online Submission Portal.
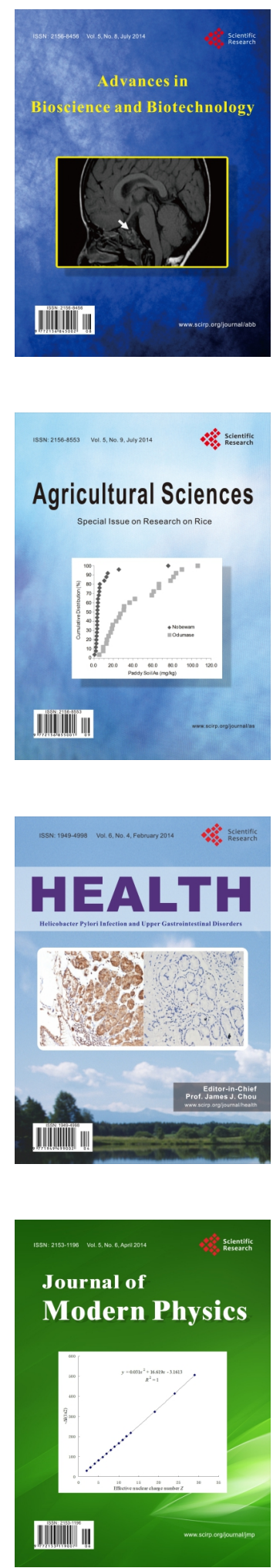
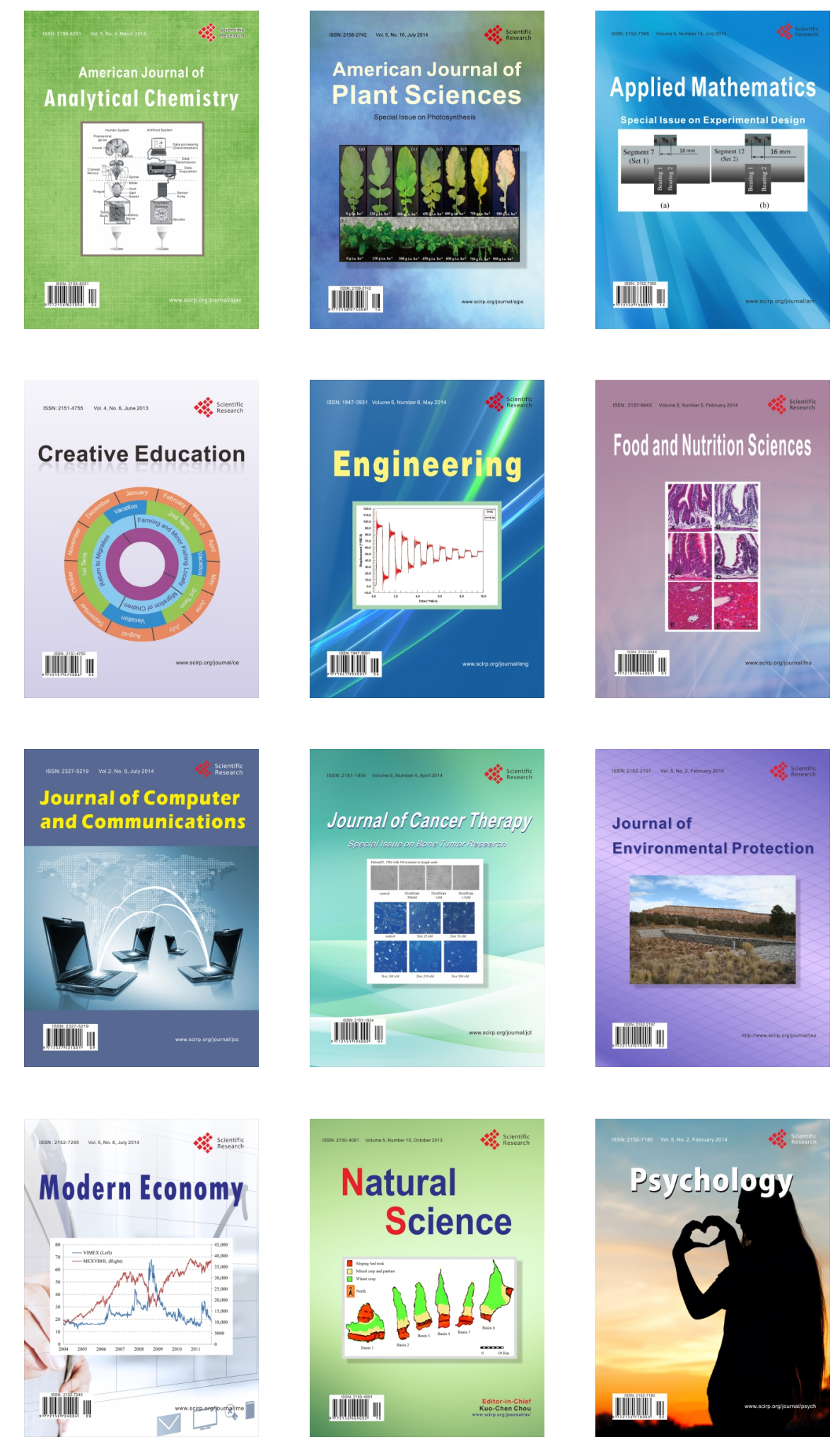